\title{
Mantle Heterogeneities and the SCEC Reference Three-Dimensional Seismic Velocity Model Version 3
}

\author{
by M. D. Kohler, H. Magistrale, and R. W. Clayton
}

\begin{abstract}
We determine upper mantle seismic velocity heterogeneities below Southern California from the inversion of teleseismic travel-time residuals. Teleseismic $P$-wave arrival times are obtained from three temporary passive experiments and Southern California Seismic Network (SCSN) stations, producing good raypath coverage. The inversion is performed using a damped least-squares conjugate gradient method (LSQR). The inversion model element spacing is $20 \mathrm{~km}$. Before the inversion, the effects of crustal velocity heterogeneities represented by the Southern California Earthquake Center (SCEC) seismic velocity model version 2 are removed from the teleseismic travel times. The $P$-wave inversion produces a variance reduction of $43 \%$. $S$-wave velocities are determined from laboratory $V p / V s$ ratios. The most prominent features imaged in the results are high $P$-wave velocities $(+3 \%)$ in the uppermost mantle beneath the northern Los Angeles basin, and the previously reported tabular high-velocity anomaly $(+3 \%)$ to depths of $200 \mathrm{~km}$ beneath the Transverse Ranges, crosscutting the San Andreas fault. We incorporate the upper mantle seismic velocity heterogeneities into the SCEC Southern California reference seismic velocity model. The prior accounting for the crustal velocity heterogeneity demonstrates the utility of the top-down method of the SCEC seismic velocity model development.
\end{abstract}

\section{Introduction}

Teleseismic travel-time inversions for $P$-wave velocity variations in the Southern California lithosphere have been computed with the goal of obtaining tomographic images. The images, in turn, provide geometric constraints to the dynamics of plate boundary deformation (e.g., Humpreys and Clayton, 1990; Kohler, 1999; Houseman et al., 2000). Recently, the use of teleseismic data has become more prevalent in the computation of wave-field modeling for seismic hazard purposes. For example, teleseismic amplitudes have been used to identify the ground-motion effects of previously unrecognized extremely low-velocity sedimentary layers in the uppermost crust (Kohler et al., 1998). Teleseisms recorded on Southern California seismometers are being used to study basin resonance and the effects of velocity gradients between tectonic regions (Prindle and Tanimoto, 2000). Short-period (10-30 sec) regional and teleseismic surface waves are being used to compute the centroid moment tensors of large Southern California earthquakes (Marcinkovich and Tanimoto, 2000). These three examples demonstrate the usefulness of including uppermost mantle velocities in a community velocity model whose main purpose is use in studies related to seismic hazard analysis. Teleseismic body waves and surface waves sample the velocity structure of the crust and upper mantle. Thus, modeling re- quires accurate mantle lithospheric velocity structure for wavelengths on the order of $10 \mathrm{~km}$. Here, we perform an inversion of teleseismic $P$-wave travel times on an unusually dense data set for upper mantle velocity structure, and describe how the results are included in the SCEC Southern California reference three-dimensional seismic velocity model.

\section{Data}

The inversion data are from several sources: the permanent short-period Southern California Seismic Network (SCSN) and several recent dense temporary seismic networks of several months duration (Fig. 1). The temporary arrays were: (1) the 1993 Los Angeles Region Seismic Experiment (LARSE I) passive phase, (2) the 1997 Los Angeles Basin Passive Seismic Experiment (LABPSE), and (3) the 19981999 Los Angeles Region Seismic Experiment II (LARSE II) passive phase (Fig. 1). Experimental details for these temporary arrays can be found in Kohler et al. $(1996,2000)$ and Kohler and Kerr (2002). The temporary experiment station density $(2-4 \mathrm{~km})$ was unprecedented in Southern California and has shed light on seismic structures in the lithosphere (Kohler, 1999; Fuis et al., 2003) that could not previously 


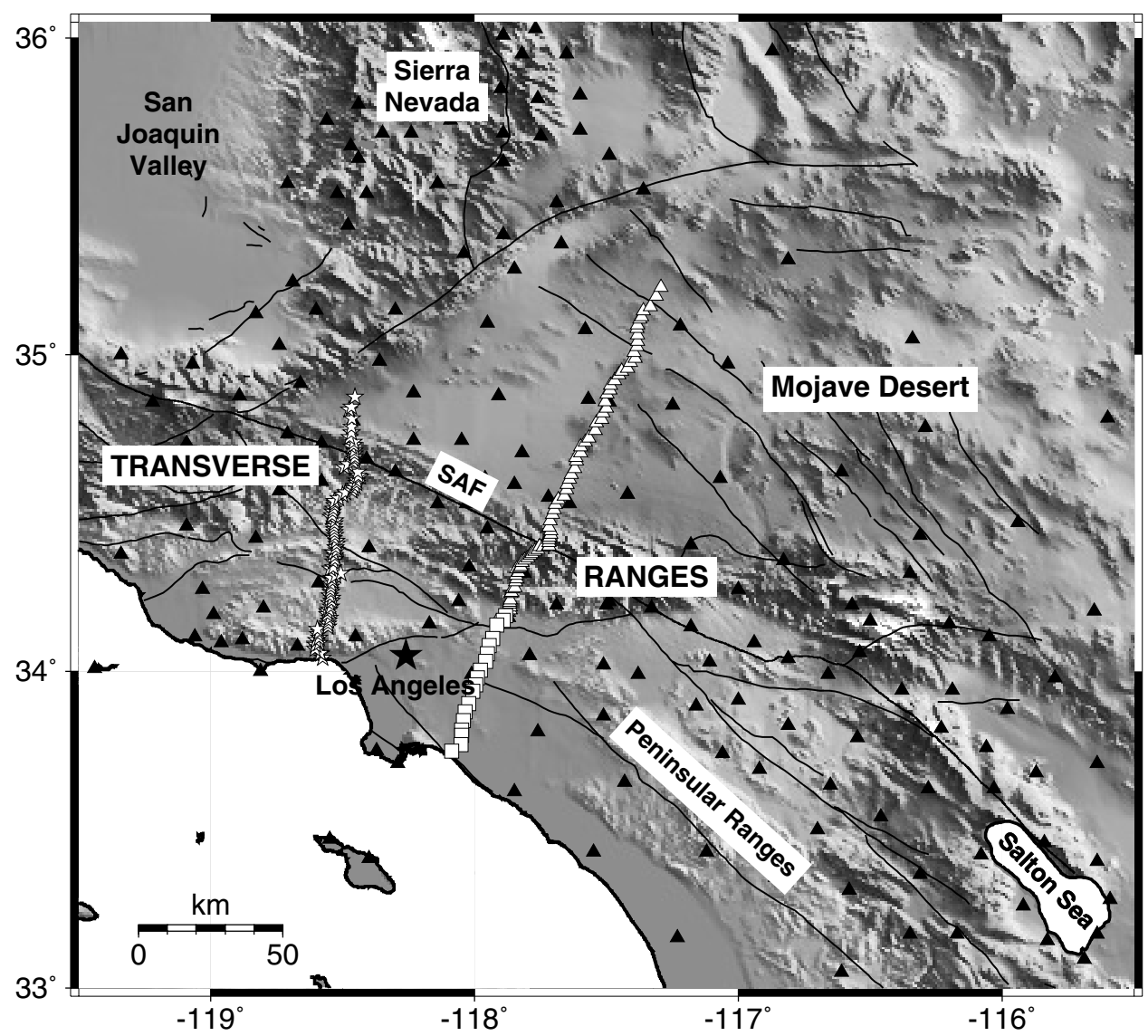

Figure 1. Map of Southern California showing the extent of the seismic velocity model version 3. Los Angeles Region Seismic Experiment (LARSE I) station locations are shown by open triangles, Los Angeles Basin Passive Seismic Experiment (LABPSE) by squares, LARSE II by stars, and Southern California Seismic Network (SCSN) by closed triangles. SAF, San Andreas Fault.

be modeled because of much larger average station spacing ( $\geq 30 \mathrm{~km}$ before 1993) resulting in spatial aliasing.

Arrival times recorded on the temporary arrays yield 3479 direct $P$-wave travel-time residuals from 132 events. The dense array teleseismic residuals were combined with $10,416 P$-wave travel-time residuals obtained from SCSN stations. The SCSN data consist of hand-picked teleseismic $P$-wave travel-time residuals compiled for several western United States tomography studies (Raikes, 1980; Humphreys et al., 1984; Humphreys and Clayton, 1990; Humphreys and Dueker, 1994). The temporary stations were distributed along transects (Fig. 1) whose locations were designed to focus primarily on localized regions within the Los Angeles basin, and the central and western Transverse Ranges. Travel-time residuals at several SCSN stations located within $10 \mathrm{~km}$ of the temporary arrays were used to calibrate the temporary array residual data. The data for each event were adjusted by a constant time shift to make them consistent with the larger number of more evenly distributed regional SCSN residuals. Events within similar backazimuth ranges were chosen for the adjustment.

\section{Inversion Method}

The travel-time residual inversions for velocity variations were computed using block parameterization covering most of Southern California (Fig. 1). The absolute teleseismic travel-time residual for the $i$ th event and $j$ th station is

$$
d_{i j}^{A}=T_{i j}^{\text {observed }}-T_{i j}^{\text {predicted }}+\Delta T_{j}
$$

where

$$
\begin{aligned}
& \Delta T_{j}=\Delta T_{\text {source }}^{\text {location }}+\Delta T_{\text {time }}^{\text {origin }}+\Delta T_{\text {lower }}^{\text {mantle }} \\
& +\Delta T_{\text {anisotropy }}+\underset{\text { Moho }}{\Delta T_{\text {crust }}}+\Delta T_{\text {mapper }}^{\text {mantle }}
\end{aligned}
$$

and the predicted travel time $T^{\text {predicted }}$ is computed using the iasp91 Earth model (Kennett and Engdahl, 1991). The advantage of using teleseismic rays is that $\Delta T_{\text {source }}, \Delta T_{\text {location }}^{\text {oring, }}$, and $\Delta T_{\text {lower }}$ antle are essentially identical for all teleseisms corresponding to the same earthquake recorded on Southern 
California stations. Therefore, when we demean the travel times for an individual event to compute the relative residuals, the contributions from those terms can be neglected. The relative residual is then

$$
d_{i j}=d_{i j}^{A}-\frac{1}{n_{j}} \sum_{j=1}^{n_{j}} d_{i j}^{A}
$$

where $n_{j}$ is the number of stations that recorded a particular event. This has the effect of removing laterally invariant velocity changes from the inversion. We did not include anisotropy in our velocity model.

Rays are back-projected from each station through initially flat-layered Earth structure and travel times are expressed as the path integral of a function of velocity and distance traveled through each depth interval in the parameter space. The travel time for the $i$ th ray is

$$
T_{i}=\int_{S_{i}} \frac{d s}{V(\vec{r})} .
$$

Using Fermat's Principle to obtain the travel time with respect to the starting model $\mathrm{V}_{0}$,

$$
T_{i}=\int_{S_{i}^{0}} \frac{d s}{V_{0}(\vec{r})} .
$$

The travel-time residual is then

$$
\begin{aligned}
\delta T_{i}=T_{i}-T_{i}^{0} \cong-\int_{S_{i}^{0}} \frac{\delta V_{p}(\vec{r})}{V_{0}(\vec{r})^{2}} d s & \\
& =\sum_{L}^{\text {\#layers }}-\left(\frac{D \cdot \delta V_{p}(\vec{r})}{V_{0}(\vec{r})^{2}}\right)_{L}
\end{aligned}
$$

where velocity perturbation $\delta V=V-V_{0}$ and distance traveled $D=\int_{S_{0}} d s$. Velocity perturbation is translated into absolute velocity by adding the inversion result for $\delta V_{p}$ to the starting $V_{p}$ value for each layer. The final product of the inversion result for the model is velocity in kilometers per second.

One of the main differences between this uppermost mantle velocity model and earlier models is that this model uses previously determined crustal velocities and Moho depth variations from the SCEC reference seismic velocity model version 2 (Magistrale et al., 2000) to remove the effects of crustal heterogeneity on the teleseismic travel times. Before inversion, each teleseismic ray is ray-traced through the three-dimensional crustal model to a depth of $45 \mathrm{~km}$, deeper than the maximum Moho depth, to ensure that the entire crust is included in the crustal correction. Rays are traced through the crust in 0.1-km-depth intervals. At each depth, the crustal velocity is computed from version 2 , and the travel-time perturbation for that interval is calculated relative to a starting model (Table 1) and removed from the travel-time residual. Because the crustal corrections are calculated with respect to a starting model, no perturbation is removed for all depths below the spatially dependent Moho, because there the model reverts to constant regional velocity values (i.e., the starting model). The choice of starting model and crustal corrections affects the top 20-50 km of the uppermost mantle. Thus, confidence in the uppermost mantle velocities should be governed by confidence in the independently determined crustal velocity heterogeneity and Moho depth variations. All arrivals were corrected for topography using a $P$-wave velocity of $5.5 \mathrm{~km} / \mathrm{sec}$.

The model space is parameterized as a three-dimensional grid with rows parallel to lines of constant latitude. The grid space corresponding to the final solution consists of 15,246 boxes (i.e., parameters) each with dimensions of $20 \mathrm{~km}$ in latitude $\times 20 \mathrm{~km}$ in longitude. Depth intervals were parameterized as layers $10 \mathrm{~km}$ thick between 10 and $30 \mathrm{~km}$ depth, and $20 \mathrm{~km}$ thick between 30 and $270 \mathrm{~km}$ depth. Note that in some regions there is overlap with the crustal model. Total grid space dimensions are $660 \mathrm{~km}$ in latitude $\times 660 \mathrm{~km}$ in longitude $\times 260 \mathrm{~km}$ in depth. The network stations were limited to those within a $420 \times 420 \mathrm{~km}$ surface area centered on the grid, but the grid is wider to allow for

Table 1

Starting Crustal Velocity Model

\begin{tabular}{cc}
\hline $\begin{array}{l}\text { Depth Range } \\
(\mathrm{km})\end{array}$ & $\begin{array}{c}P \text {-Wave Velocity } \\
(\mathrm{km} / \mathrm{sec})\end{array}$ \\
\hline $0-5$ & 5.5 \\
$5-10$ & 6.0 \\
$10-20$ & 6.25 \\
$20-25$ & 6.5 \\
$25-28$ & 6.7 \\
$28-45$ & 7.8 \\
\hline
\end{tabular}

Table 2

Starting $P$-Wave Velocity Model for Inversions

\begin{tabular}{cc}
\hline $\begin{array}{l}\text { Depth Range } \\
(\mathrm{km})\end{array}$ & $\begin{array}{c}P \text {-Wave Velocity } \\
(\mathrm{km} / \mathrm{sec})\end{array}$ \\
\hline $10-20$ & 6.2 \\
$20-30$ & 6.8 \\
$30-50$ & 7.8 \\
$50-70$ & 7.8 \\
$70-90$ & 7.9 \\
$90-110$ & 8.0 \\
$110-130$ & 8.1 \\
$130-150$ & 8.1 \\
$150-170$ & 8.1 \\
$170-190$ & 8.1 \\
$190-210$ & 8.1 \\
$210-230$ & 8.2 \\
$230-250$ & 8.3 \\
$250-270$ & 8.4 \\
\hline
\end{tabular}



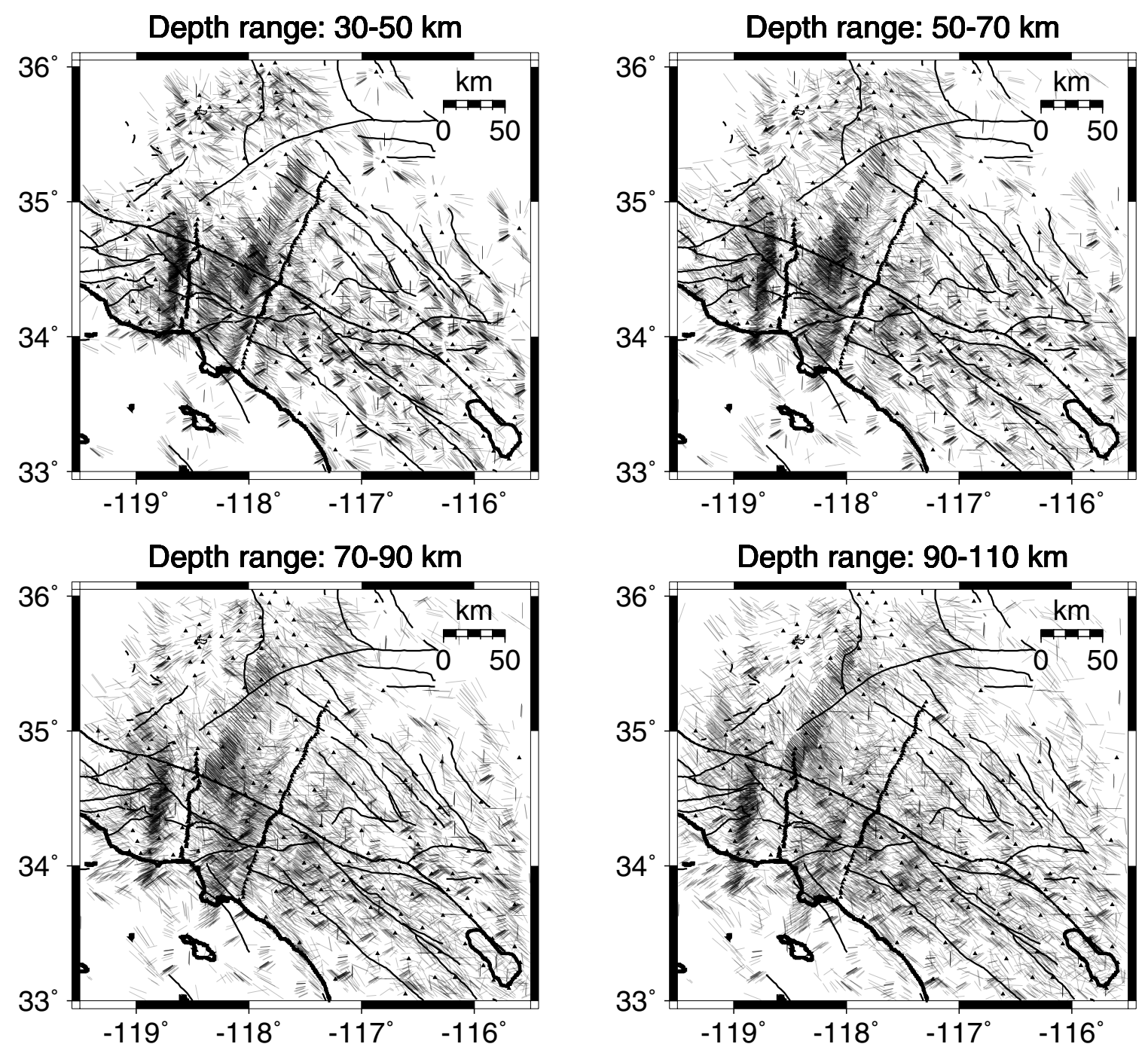

Depth range: $110-130 \mathrm{~km}$
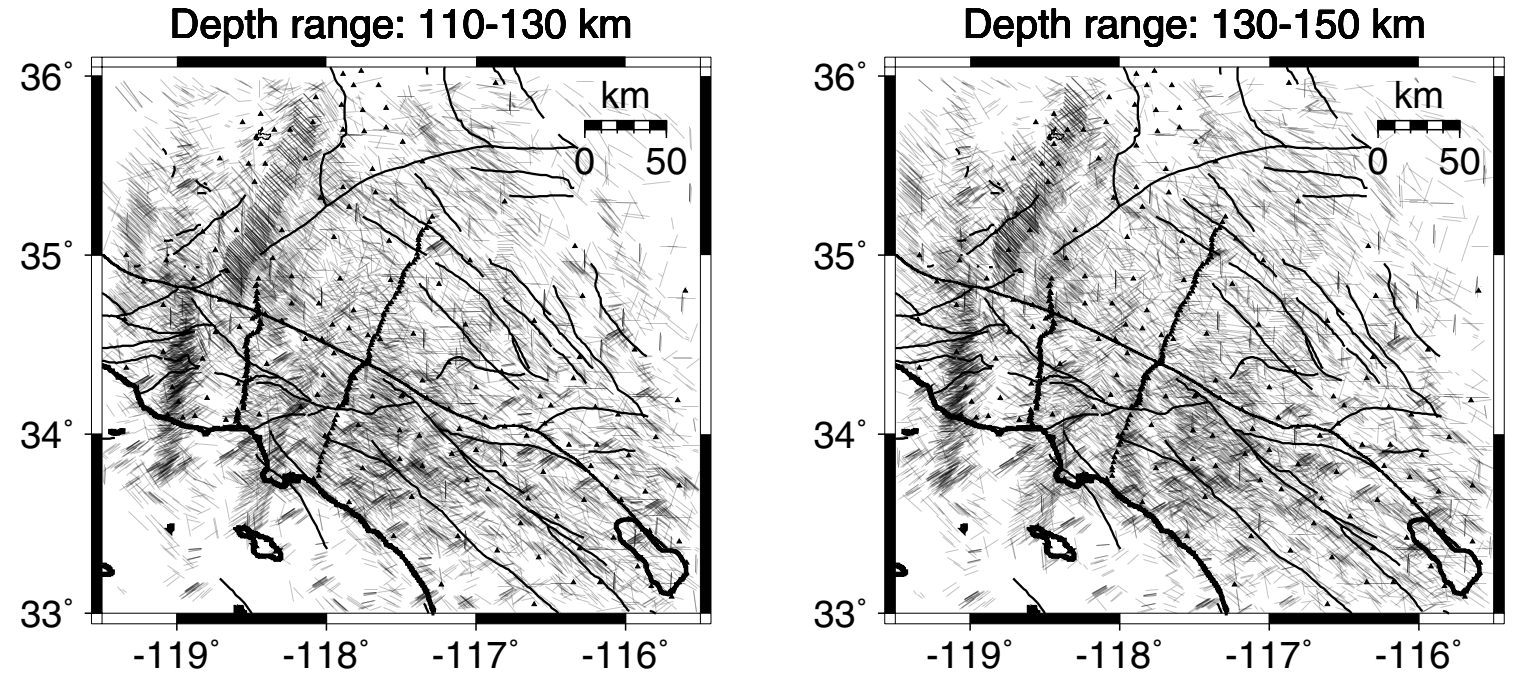

Figure 2. Teleseismic raypath segments for depth intervals given in Table 2 showing raypath coverage within each inversion layer. Raypath coverage is dense within most of the inversion volume but sparse in the corners and near the edges where there are no stations. Corresponding velocity perturbation structures are shown in Figure 7. 

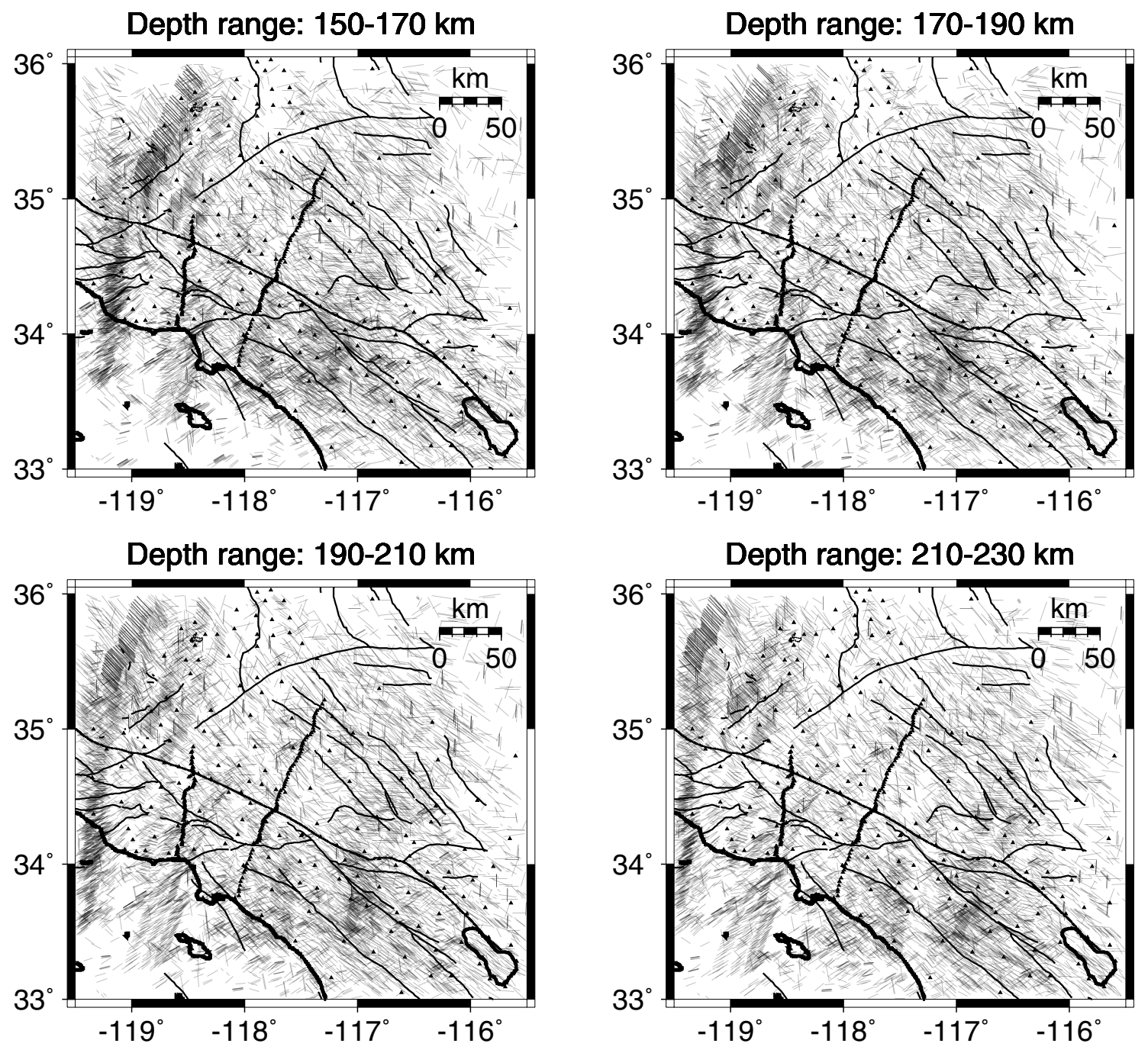

Depth range: $230-250 \mathrm{~km}$
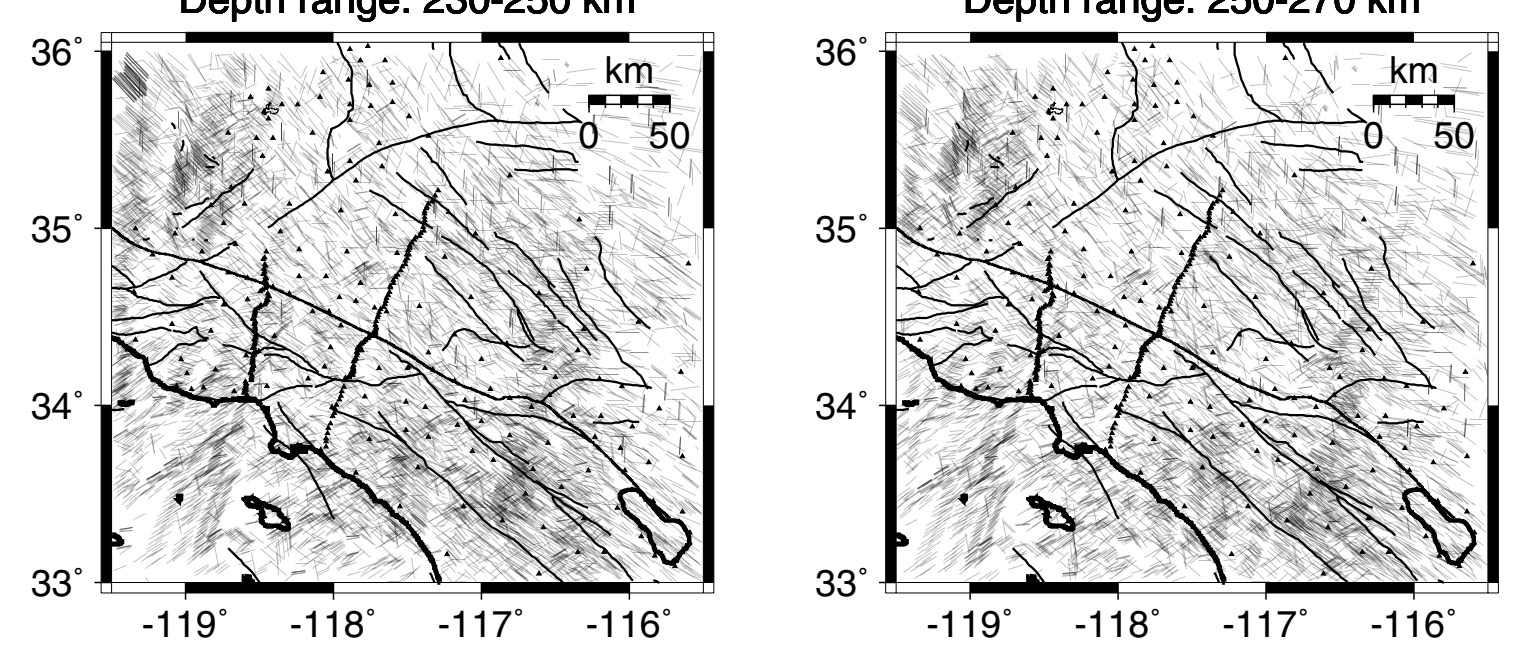

Figure 2b. 
nonvertical ray projection. This parameterization represents a reasonable choice based on the resolution and root-meansquare (rms) travel-time fit trade-off. Raypath coverage within the boxes is best near the temporary arrays, but remains relatively uniform at most depths and distances from the array. Final tomographic images are obtained by linearly interpolating between the centers of each box. The onedimensional model used in our inversions, shown in Table 2, is based on the iasp91 model (Kennett and Engdahl, 1991) modified for Southern California by using the model of Hadley and Kanamori (1977).

Inversion solutions were obtained by the damped leastsquares LSQR conjugate gradient method for sparse matrices (Paige and Saunders, 1982a,b). The travel-time residuals for each ray are expressed as a function of velocities through each grid element multiplied by unknown velocity perturbations and summed along the raypath; the velocity in each grid element is assumed constant. The linear equations are $\mathbf{A x}=\mathbf{b}$ where the elements of matrix $\mathbf{A}$ are the coefficients arising from the summed velocity functions, the elements of $\mathbf{x}$ are the unknown velocity perturbations for which we solve, and elements of $\mathbf{b}$ are the travel-time residuals. After five iterations, the change in final rms travel-time fit values was insignificant. The largest decrease in rms values took place after the first iteration. Final rms values were $\sim 0.16$ sec, slightly larger than a typical measurement error, corresponding to a variance reduction of $43 \%$. Damping was chosen that represented a balanced trade-off between smoothness of model and fit to the data. We wanted the images to be smooth enough to evaluate large structures but also so that the travel-time residuals were not overfit. This is an underdetermined problem and some of the boxes in the grid space were not sampled by any rays.

Our teleseismic data do not allow determination of $S$ wave travel times for various reasons. In many cases the seismometers were only vertical-component instruments. When there are three components, the signal-to-noise ratio is usually too low to determine teleseismic $S$-wave travel times independently. We use experimentally determined values for $V p / V s$ as a function of temperature (Anderson and Isaak, 1995) to obtain $V s$ assuming a thermal gradient of $15^{\circ} \mathrm{C} / \mathrm{km}$ (Artemieva and Mooney, 2001). We do not consider the effect of potential compositional variations on $V p / V s$.

\section{Resolution Tests}

Raypath coverage is not uniform and we expect better resolution where the raypaths are denser. In anticipation of resolution tests, we computed the geographical locations for the segments of all raypaths that lie between the inversion grid depth intervals. The resulting raypath segments are shown in Figure 2 and they distinguish regions where raypath coverage is uniform and dense from where it is sparse. Despite increased ray concentration from the LARSE data, the images do not appear to be biased by it. Damping applied in the inversions is counteracting the addition of those rays. The uppermost mantle velocity variations described in the next section should be viewed in light of the raypath coverage and the following resolution tests. (a)

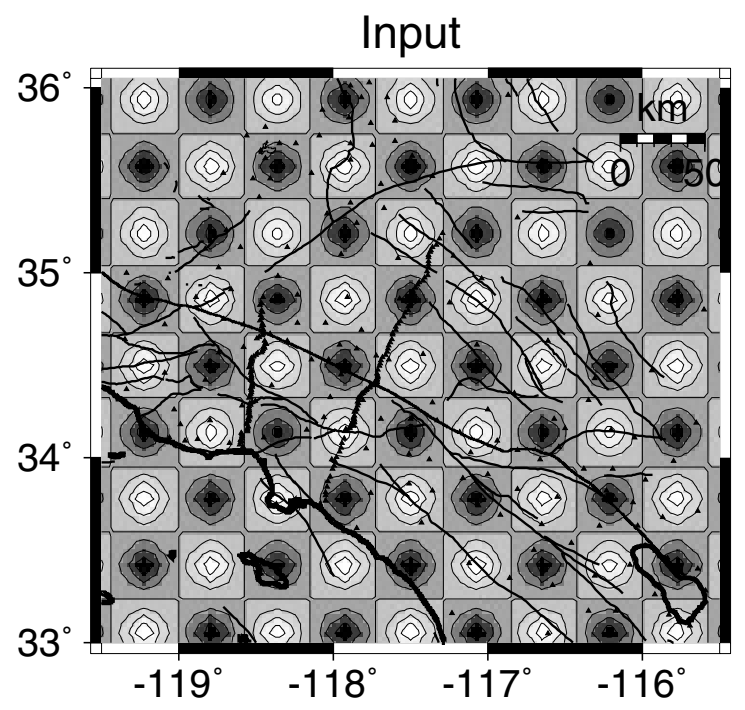

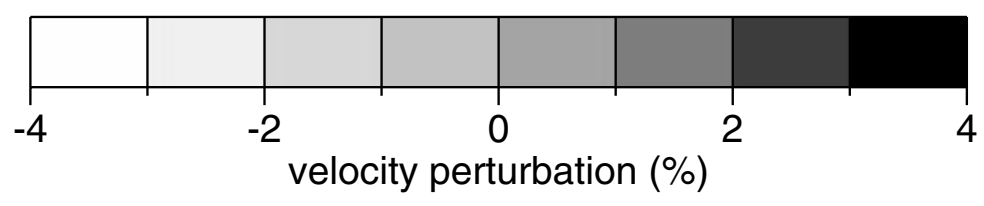

Figure 3. (a) Input checkerboard Earth structure where amplitudes are assigned to vary between $-4 \%$ and $+4 \%$ at all depths. (b) Results from checkerboard resolution test for depths of 40, 70, 110, 150, 190, and $230 \mathrm{~km}$ showing how pattern and amplitude recovery vary on a horizontal length scale of $40 \mathrm{~km}$. 

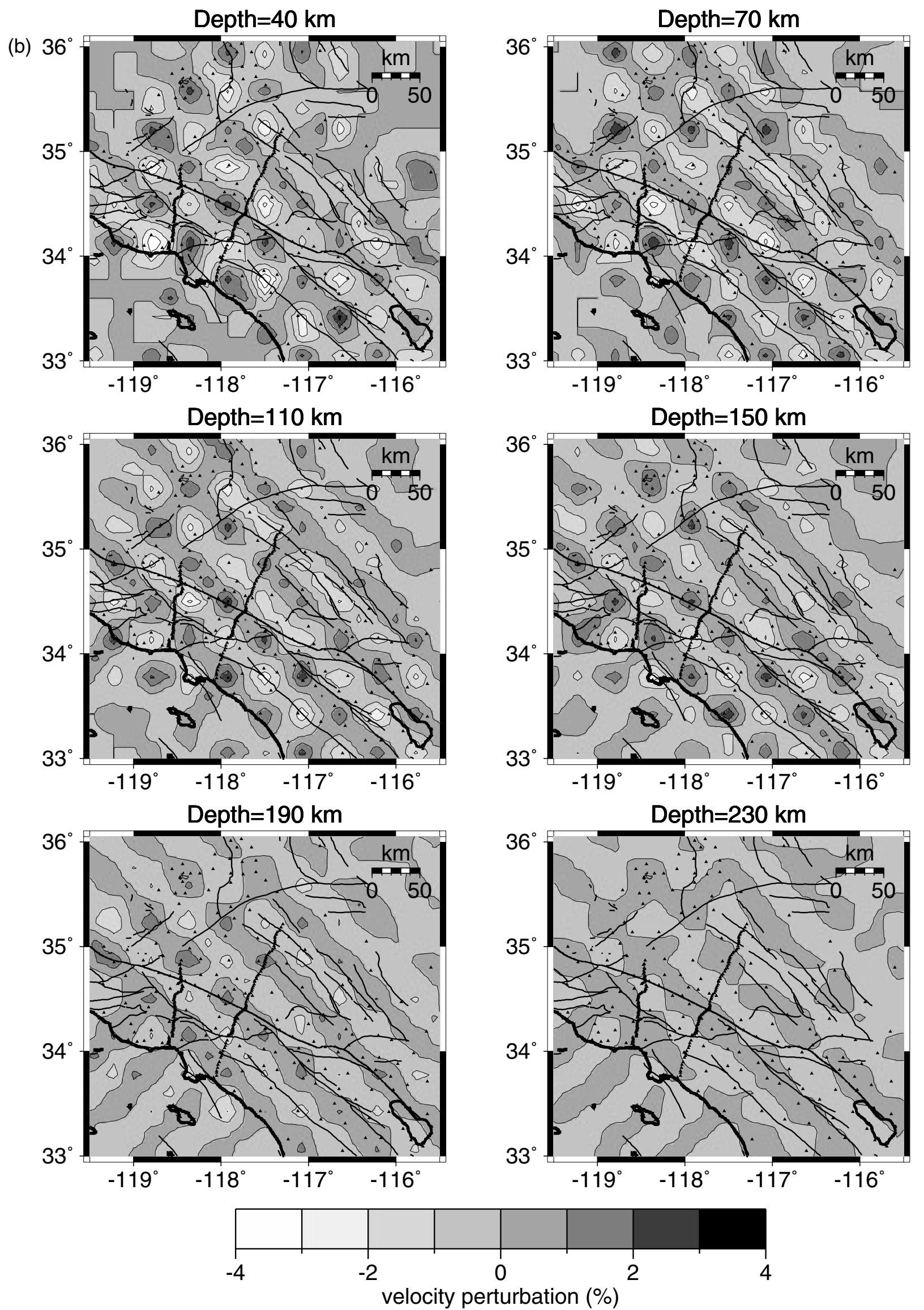

Figure $3 b$. 
To assess the resolution of our images at different wavelengths, we performed several resolution tests using different synthetic Earth structures. The inversions use the same inversion parameters (e.g., number of data and earthquakes, raypath coverage, damping, number of iterations, etc.) as the real-data inversions and illustrate where velocity anomaly amplitudes may be diminished or geometries distorted. For the first test, initial checkerboard Earth structure was defined with amplitudes assigned so that input structure varied between $-4 \%$ and $+4 \%$ at all depths. The horizontal dimensions of the boxes are $40 \times 40 \mathrm{~km}$. Rays were projected through the synthetic Earth models and the resulting synthetic travel-time residuals were inverted for Earth structure. Initial patterns and results are shown in Figure 3 for depths of 40, 70, 110, 150, 190, and $230 \mathrm{~km}$. Recovered synthetic Earth structure has a pattern similar to the input pattern for most of the inversion volume. Recovery remains strong where raypath coverage is good but grows poorer for deeper layers, and for regions in the northeast and southeast corners of the inversion volume. Not much horizontal smearing occurs, but amplitudes are reduced with increasing depth.

The most pronounced reduction in pattern and amplitude recovery takes place in the corners of the mapped region where there is the least raypath coverage because of a lack of stations. In these regions, the checkerboard pattern on a length scale of $40 \mathrm{~km}$ is not recovered and amplitudes are near zero. Resolution in the offshore region is aided by measurements taken on island stations, but in general, interpretations about the three-dimensional extent of structures be- low the Pacific Ocean or in the Mojave Desert cannot be made at the checkerboard test pattern length scale. Maximum recovered velocity amplitude is up to $75 \%$ relative to the initial earth structure for depths less than $150 \mathrm{~km}$. It decreases to $20 \%$ for depths approaching the bottom of the inversion volume.

The second set of resolution inversions was performed to test how anomalies at depth were recovered in various regions within the model. The input anomaly locations were chosen to test areas with good and poor ray coverage, and areas with tectonic features of interest. The synthetic input models consisted of vertical, single-block anomalies at points within the inversion volume. Each block is $80 \times 80$ $\mathrm{km}$ in dimension and extends from 10 to $270 \mathrm{~km}$ in depth. The input structure was assigned $+4 \%$ at all depths. Figure 4 shows the input and inversion output structure for the first block-resolution test. The block location features a region with good raypath coverage and covers the western extent of the Transverse Ranges high-velocity mantle anomaly. The resolution inversion result shows good recovery for depths less than $150 \mathrm{~km}$, but diminishing amplitudes below that because of diminishing raypath density. Horizontal smearing is not a problem because of the relatively even raypath distribution. The second test location (Fig. 5) was chosen to analyze structures in the Peninsular Ranges region where raypath coverage is reasonably good. The result, as before, indicates that horizontal resolution at this wavelength is good, but that amplitudes are diminished with depth. The third test area was chosen for its sparser raypath coverage
Input

(a)

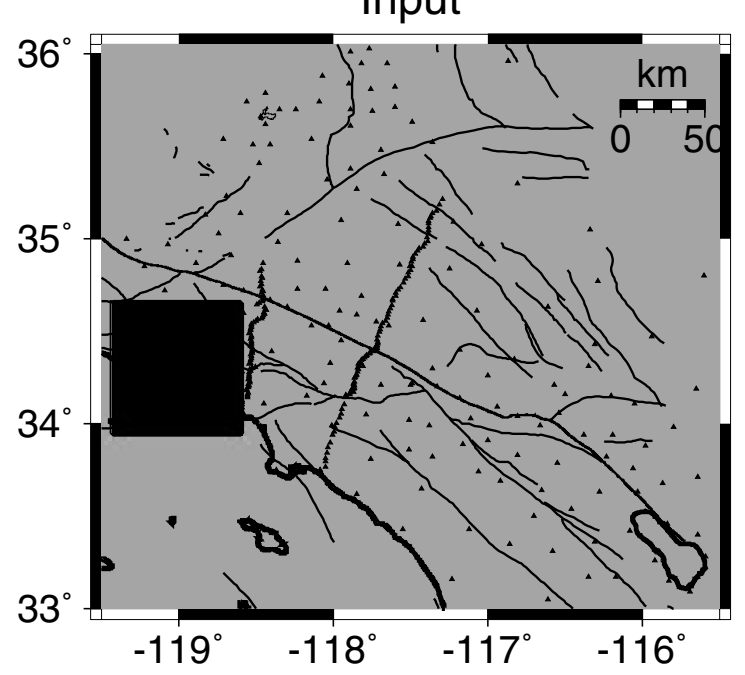

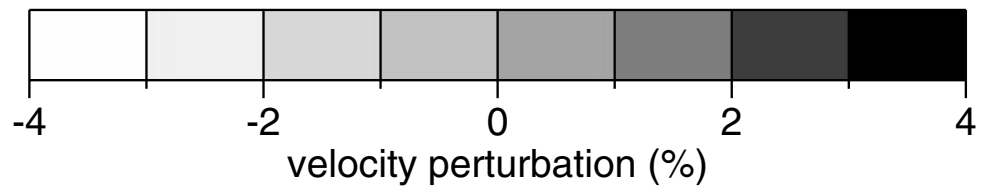

Figure 4. (a) Input pattern with amplitude assigned $+4 \%$ for vertical-block resolution test 1 to test a region with good raypath coverage in the western Transverse Ranges. (b) Results of test 1 showing anomaly pattern and amplitude recovery at various depths. 

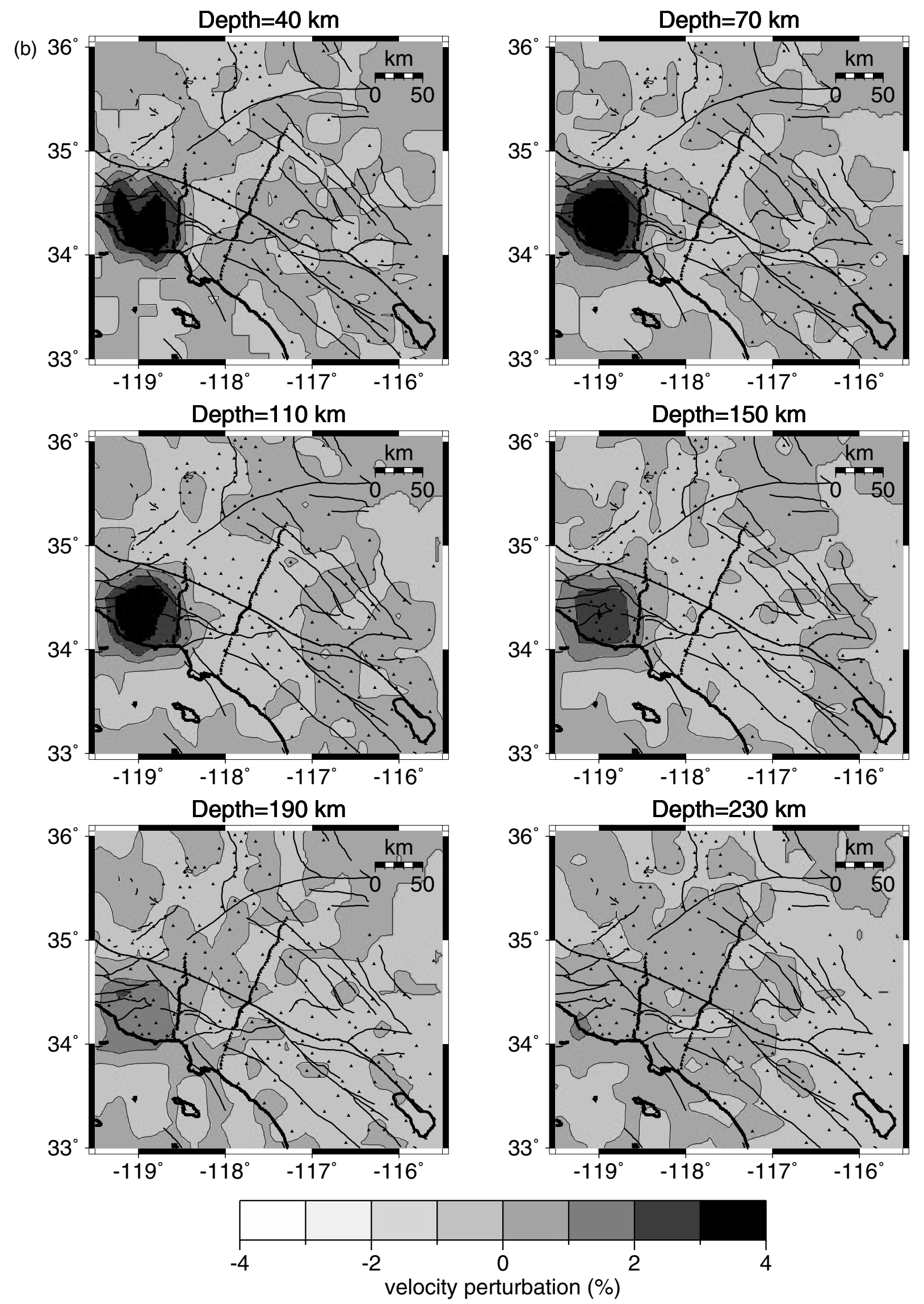

Figure $4 \mathrm{~b}$. 
(Fig. 6). The result shows amplitudes diminishing more rapidly with depth compared with the other resolution tests, even in the uppermost layers, because raypath coverage is not as good as elsewhere in the inversion volume. The addition of the dense temporary array data has improved resolution in the vicinity of the array stations.

The major features imaged in the current study are larger than the checkerboard elements (Fig. 3), so recovery of the resolution test patterns represents a worst-case test of our imaging ability. In general, pattern and amplitude recovery from the resolution tests indicate that resolution at horizontal length scales of $40-80 \mathrm{~km}$ is good for depths between 40 and $80 \mathrm{~km}$ (Figs. 3-6), with amplitudes decreasing rapidly in some cases (e.g., Figs. $4 b$ and $6 b$ ). Horizontal smearing grows more prominent as pattern recovery diminishes for a particular wavelength and amplitude (e.g., parallel and perpendicular to the LARSE arrays in Fig. 3b). The Transverse Ranges region exhibits the greatest degree of anomaly recovery of all regions (Fig. 3b) providing bounds on our interpretation of the depth extent of the high-velocity anomaly. For example, the resolution test shown in Figure 4 indicates that anomalies obtained from inversions for real Earth structure below the western Transverse Ranges are probably exhibiting at least $75 \%$ of true anomaly for depths to $150 \mathrm{~km}$. At depths around $190 \mathrm{~km}$, the horizontal extent of the anomaly is still relatively well determined, but less than $50 \%$ of the amplitude is being recovered. At depths greater than $230 \mathrm{~km}$, neither the location nor the anomaly amplitude can be determined with any certainty.

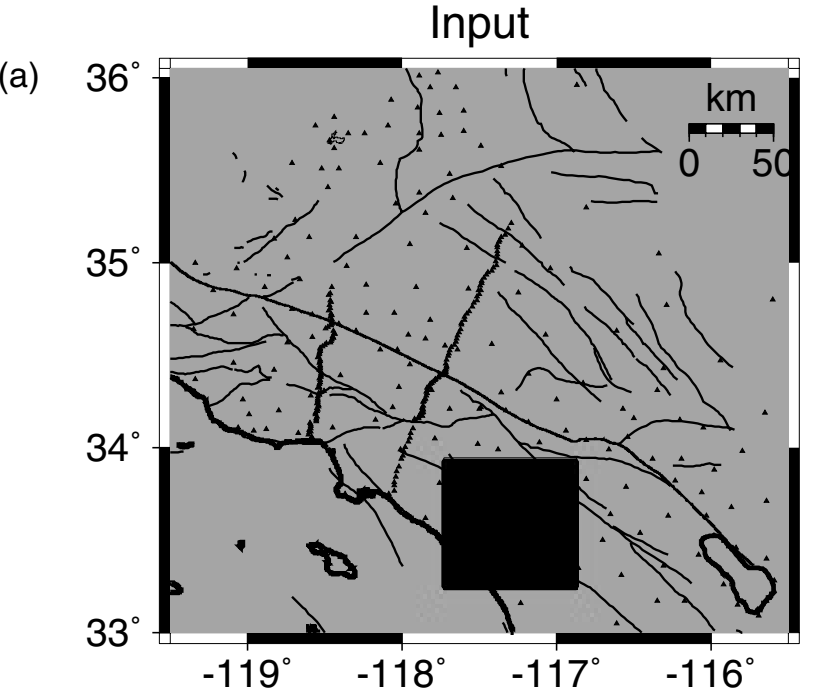

\section{Upper Mantle Velocity Variations}

Tomographic images resulting from the teleseismic travel-time inversions are shown in Figures 7 and 8 . The perturbations are relative to the starting model (Table 2) although the choice of velocities in the starting model does not significantly affect the solution. Velocities are mapped at the midpoint of each depth interval and are linearly interpolated for different depths. Velocities have been mapped both as perturbations (Fig. 7) and as absolute velocities (Fig. 8). Each set of images illustrates different aspects of the model. Perturbations illustrate variations among structural features and are useful for investigating the spatial extent and geometry of heterogeneities. Absolute velocities are better suited for applications that require tracking and removing the effects of the mantle velocity field on teleseisms or surface waves.

The tomographic images show that heterogeneity is closely associated with tectonic features, in particular, the Transverse Ranges and the San Andreas fault. The figures illustrate that the high-velocity anomaly is mainly an eastwest feature as reported previously (Humphreys and Clayton, 1990), not parallel everywhere to the San Andreas fault. The anomaly extends well into the Mojave Desert, and its location and width $(60-80 \mathrm{~km})$ coincide with the zone of convergence that is causing uplift of the Transverse Ranges. There appears to be a slight counterclockwise rotation of the anomaly with depth from an east-west orientation at $50 \mathrm{~km}$ depth to east-northeast-west-southwest at up to $190 \mathrm{~km}$

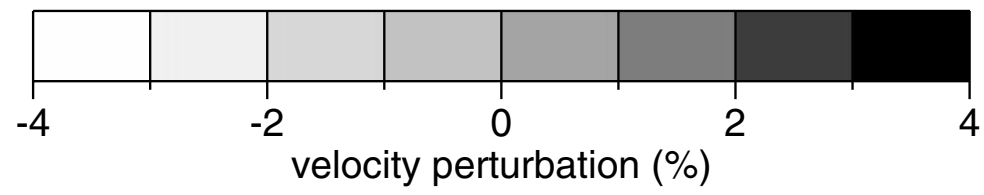

Figure 5. (a) Input pattern with amplitude assigned $+4 \%$ for vertical-block resolution test 2 to test a region with reasonably good raypath coverage in the Peninsular Ranges. (b) Results of test 2 showing anomaly pattern and amplitude recovery at various depths. 

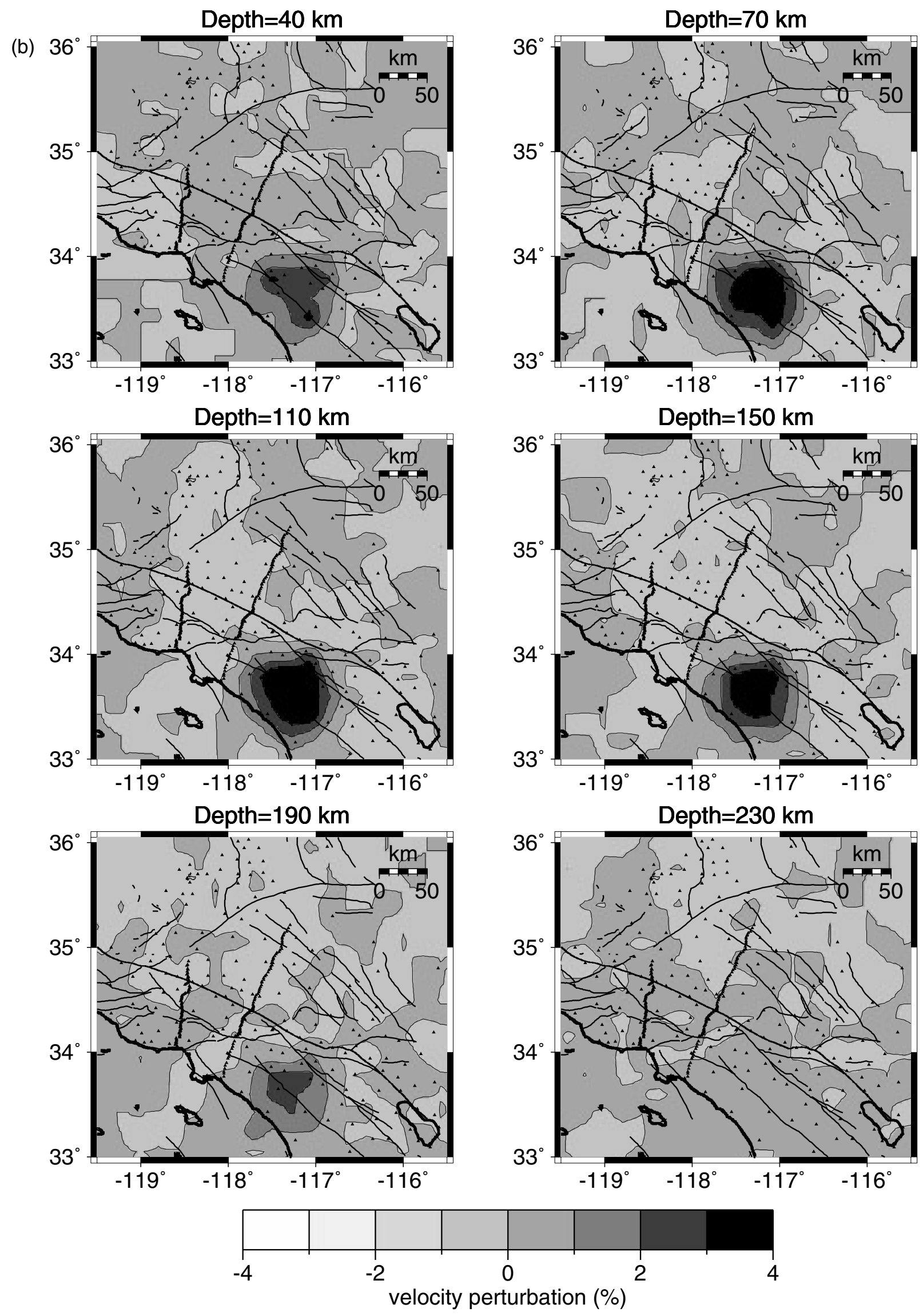

Figure $5 b$. 
depth. The western end breaks up at about $150 \mathrm{~km}$ depth and the eastern end by $200 \mathrm{~km}$ depth implying lithospheric thickening of $50 \%$ and $100 \%$, respectively, assuming an initial thickness of $\sim 100 \mathrm{~km}$ (Humphreys and Hager, 1990). In both cases, the high velocities become more dispersed with increasing depth.

Our tomographic results suggest that the cold, presumably dense mantle downwelling directly underlies thickened crust, contrary to previous studies. Below the central Transverse Ranges, the anomaly extends up to the base of a 10$\mathrm{km}$-thick crustal root centered on the San Andreas fault (Kohler, 1999) without spreading laterally below the crust on each side of the San Gabriel Mountains (Fig. 7). This observation has led to the suggestion that the lower crust and uppermost mantle are mechanically coupled in a gravitationally unstable thickening process (Houseman et al., 2000).

Below the western Transverse Ranges, high velocities also underlie thickened crust documented in Magistrale et al. (2000) but are centered south of the San Andreas fault (Fig. 9). Whether the San Andreas shear-strain field contributes to the location and geometry of the dense mantle downwelling remains to be determined. The San Andreas fault strike-slip deformation field is almost perpendicular to the convergent region, and the strike-slip component of plate motion ( $30-35 \mathrm{~mm} / \mathrm{yr})$ is $1.5-2.3$ times larger than the total convergence rate $(15-20 \mathrm{~mm} / \mathrm{yr}$ ) (Jackson and Molnar, 1990; Feigl et al., 1993; Shen et al., 1996; Snay et al., 1996). A relatively low effective viscosity estimate of $\leq 10^{21} \mathrm{~Pa} /$ sec (Houseman et al., 2000) and a low regional average $P$ - wave velocity of $\leq 7.8 \mathrm{~km} / \mathrm{sec}$ (Hadley and Kanamori, 1977; Hearn and Clayton, 1986; Richards-Dinger and Shearer, 1997) could be evidence for the effect of San Andreas fault strike-slip shear weakening of the Southern California mantle lithosphere.

Our observations that the upper mantle anomaly below the eastern Transverse Ranges extends to greater depths where the crust is thicker (Magistrale et al., 2000) than the western end may be evidence for a higher convergence rate or longer period of convergence in the eastern Transverse Ranges as suggested by fission-track data (Blythe et al., 2000). There is also high spatial correlation between the depth of the intact mantle downwelling and topography. In the central Transverse Ranges close to the LARSE I array, the downwelling extends to at least $200 \mathrm{~km}$ and the topography reaches over $2.3 \mathrm{~km}$. In the western Transverse Ranges close to the LARSE II array where the mantle downwelling only extends to about $150 \mathrm{~km}$ depth, the maximum topography is $1.2 \mathrm{~km}$. Elevations in the eastern Transverse Ranges are up to $3 \mathrm{~km}$, where the mantle anomaly exhibits the largest amplitude and greatest depth extent (Fig. 7).

\section{SCEC Version 3 Model}

The upper mantle seismic velocity heterogeneities determined herein are mated to the SCEC version 2 crustal seismic velocity model (Magistrale et al., 2000) to produce the version 3 model. The version 2 model was developed in a top-down fashion, starting with shallow layers in Los Angeles area sedimentary basins, detailed shallow basin veloc-

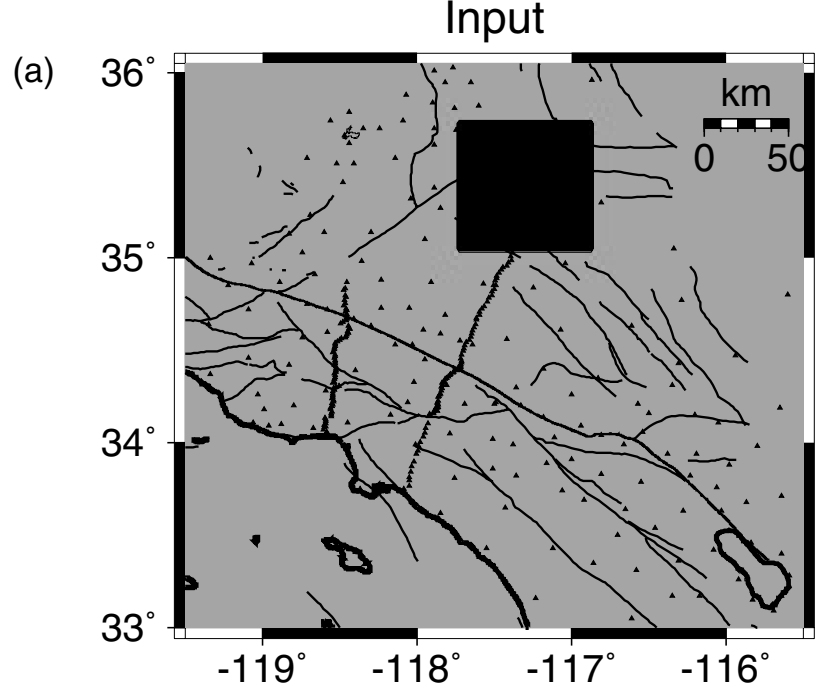

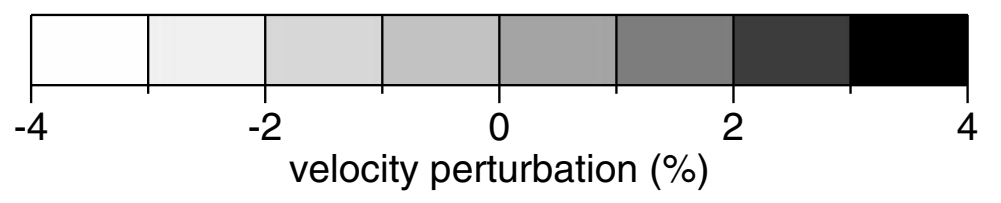

Figure 6. (a) Input pattern with amplitude assigned $+4 \%$ for vertical-block resolution test 3 to test a region with sparser raypath coverage in the northern Mojave Desert region. (b) Results of test 3 showing anomaly pattern and amplitude recovery at various depths. 

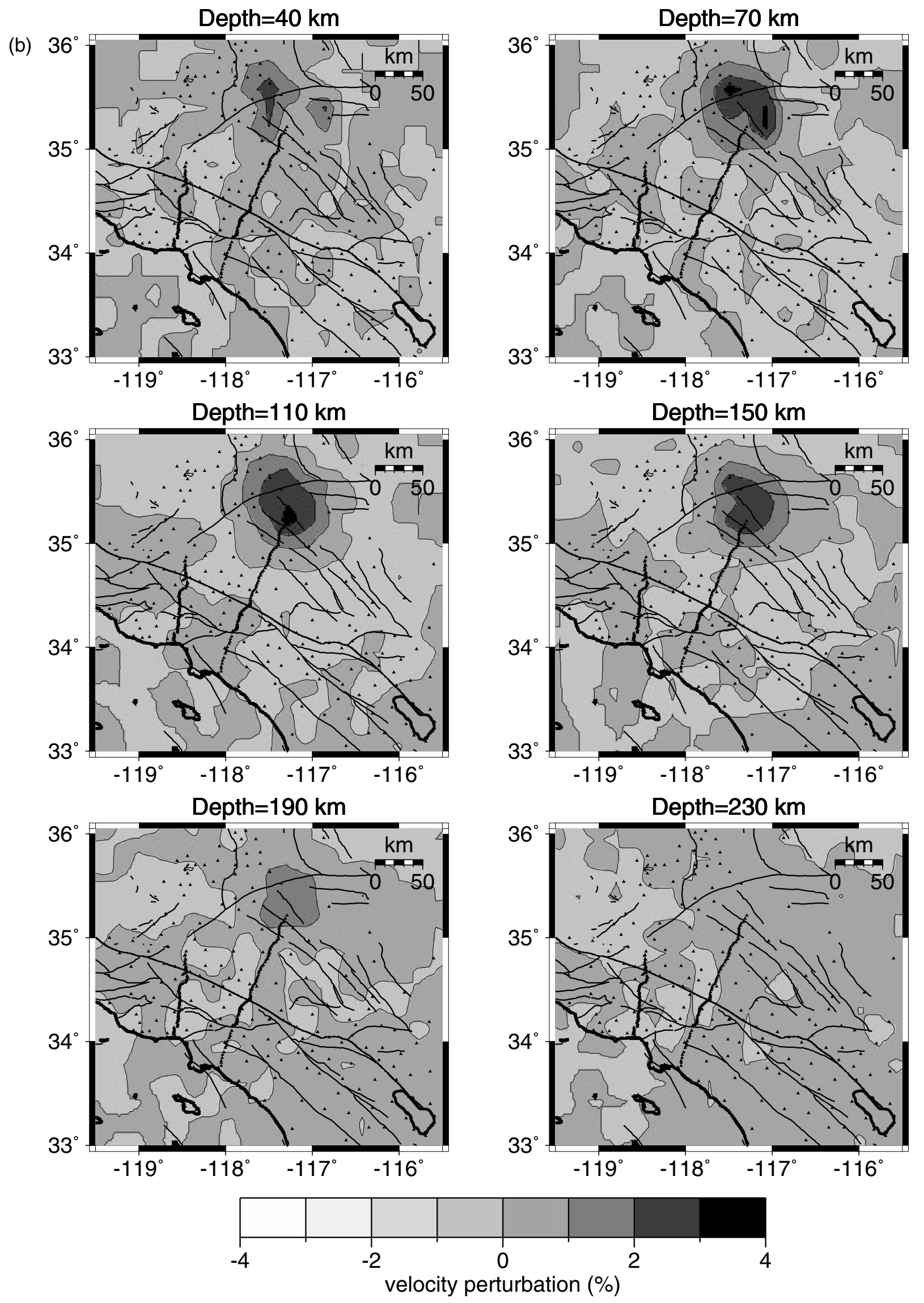

Figure $6 b$. 

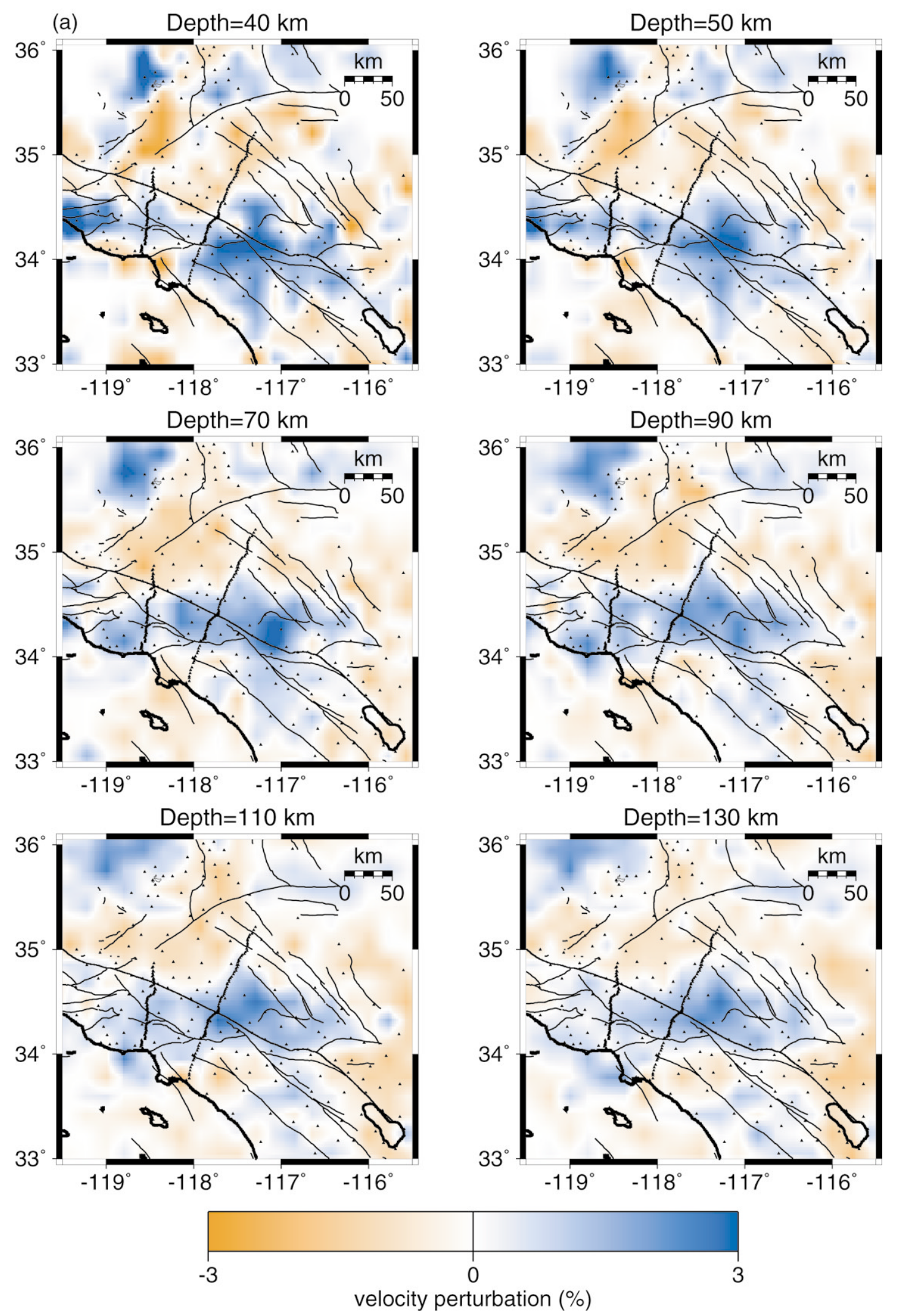

Figure 7a. Plan view images of $P$-wave velocity variations below Southern California resulting from the inversion of the teleseismic travel-time perturbations using crustal velocities from the Southern California reference seismic velocity model version 2 . 
(b)

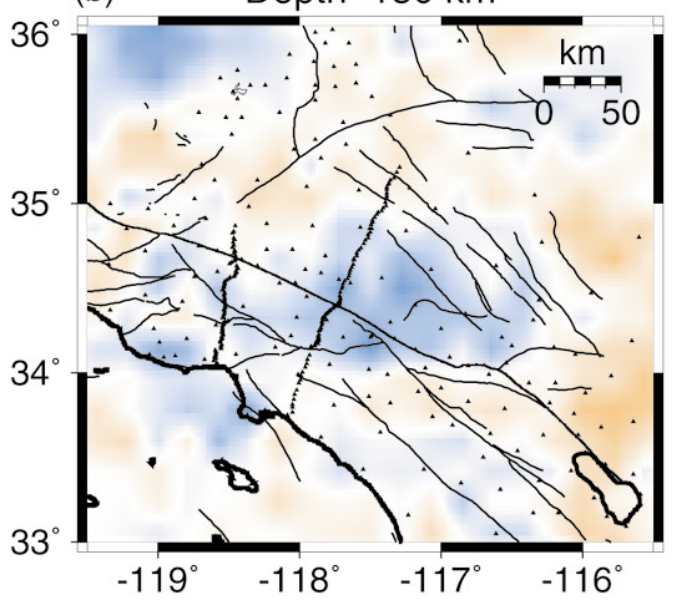

Depth $=190 \mathrm{~km}$
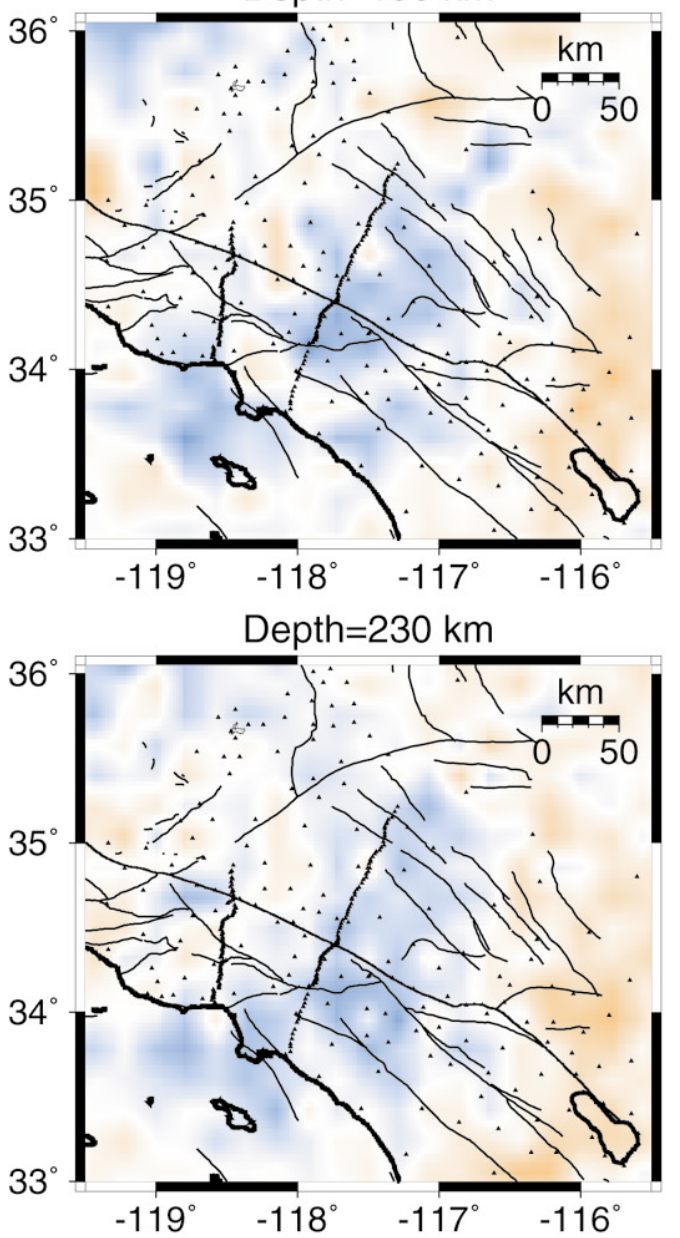
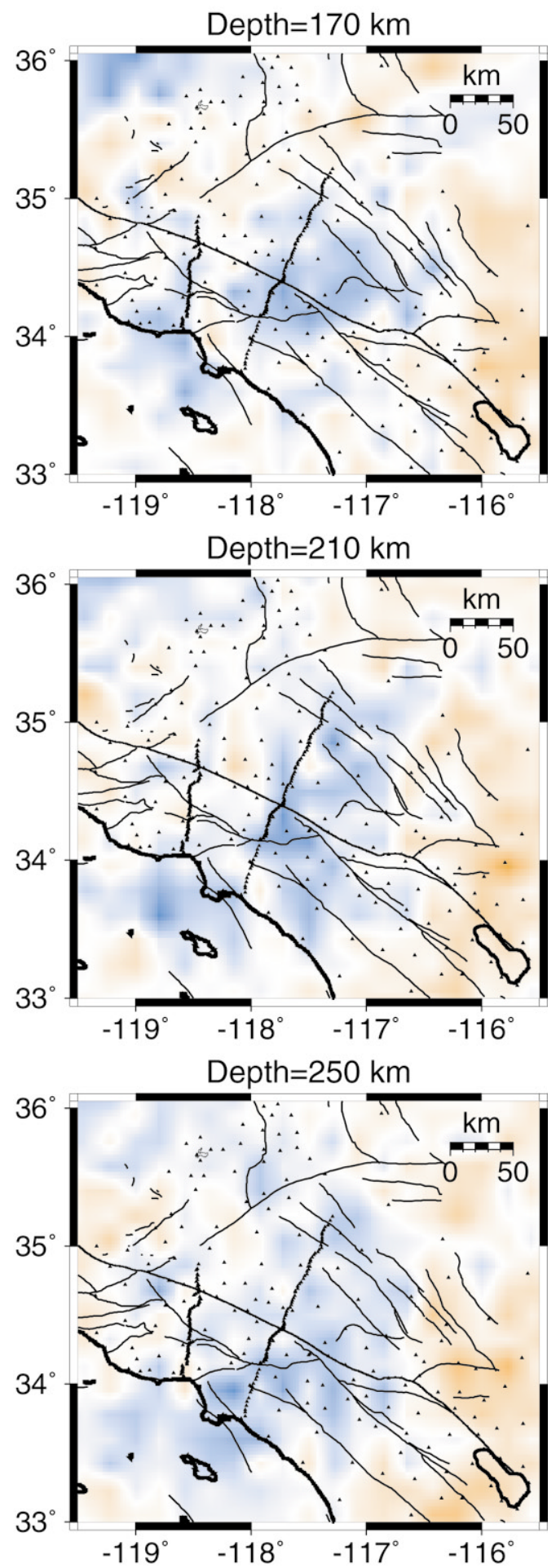

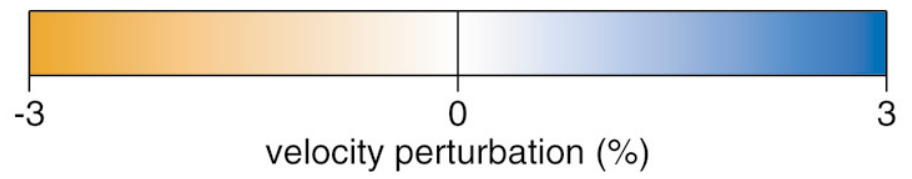

Figure $7 \mathrm{~b}$. Note the scale at the bottom that shows where velocity perturbations are different from $0 \%$ relative to the starting model (Table 2). The uppermost mantle velocities in the Southern California reference seismic velocity model version 3 (described by this article) were obtained by adding the perturbations shown here to the starting model. 
ities from geotechnical logs, three-dimensional crustal velocities outside of the sedimentary basins, a crude Salton trough model, and a laterally varying Moho. The top-down approach allows us to account for the influence of shallow elements on travel times as each deeper element is added, producing a self-consistent model. Here, we corrected the more densely recorded teleseismic travel times for the crustal contribution (as modeled by version 2), producing a sharper image of the upper mantle variations.

Version 3 of the reference three-dimensional seismic velocity model for Southern California is available as a FORTRAN source code and can be found on the SCEC Data Center website at http://www.scecdc.scec.org. The user queries the code for velocities at a set of longitude-latitude-depth points; the output is $V p, V s$, and density at those points. The model produces upper mantle $V p$ and $V s$ values at a point of interest by interpolation of the velocities of the eight inversion grid elements surrounding the point. The $V p$ values are directly from the inversion results (e.g., Fig. 8). The $V s$ values are calculated from laboratory $V p / V s$ determinations (described in a previous section) and assigned to the appropriate inversion grid elements. Densities are derived from $V p$ as described in Magistrale et al. (2000). Points in the uppermost mantle outside the inversion volume are assigned velocities from the one-dimensional starting model (Table 2).

With the inclusion of the upper mantle velocity heterogeneities, the version 3 model achieves a multiscale resolution appropriate for a variety of tectonic modeling applications. In particular, seismic heterogeneity is a valuable physical constraint when determining what rheological conditions can enable crustal thickening and the development of a dense mantle lithospheric root (e.g., Houseman et al., 2000). The goal of version 3, as a reference model, is to present an uppermost mantle seismic velocity model that is consistent with a large travel-time data set but that can be further tested and refined by additional independent data sets. Ultimately the final model will be the best representation of a number of independent data sets that has been refined by subsequent testing and updating.

\section{Conclusions}

Teleseismic $P$-wave travel-time residuals are inverted for uppermost mantle velocity heterogeneities below Southern California. The resulting upper mantle structure is added to previously determined crustal structure to form the SCEC Southern California reference three-dimensional seismic velocity model version 3 . Inversion data included arrival times calculated from three temporary passive seismic experiments and SCSN stations. New interpretations of spatial variations in the crust-mantle relationship are made possible by the multiscale model. High-velocity upper mantle underlies thickened crust of the eastern and western Transverse Ranges suggesting coupled crust-mantle lithospheric thickening and downwelling. The Transverse Ranges uppermost mantle anomaly gradually becomes more east-northeast-

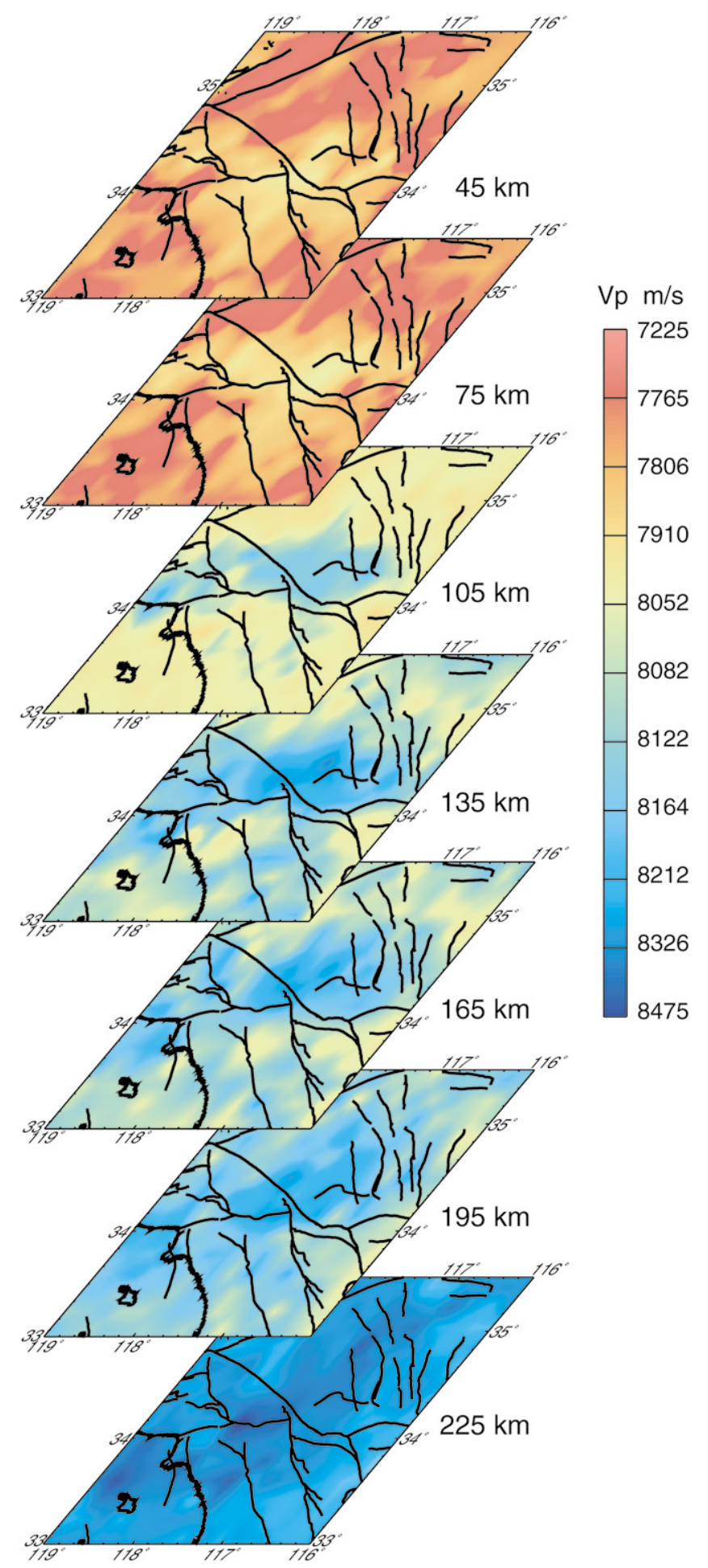

Figure 8. Stack diagram showing absolute velocities in the crust and upper mantle. This figure shows an example of the product a user will receive upon requesting $P$-wave velocities at a series of longitudelatitude-depth points. 

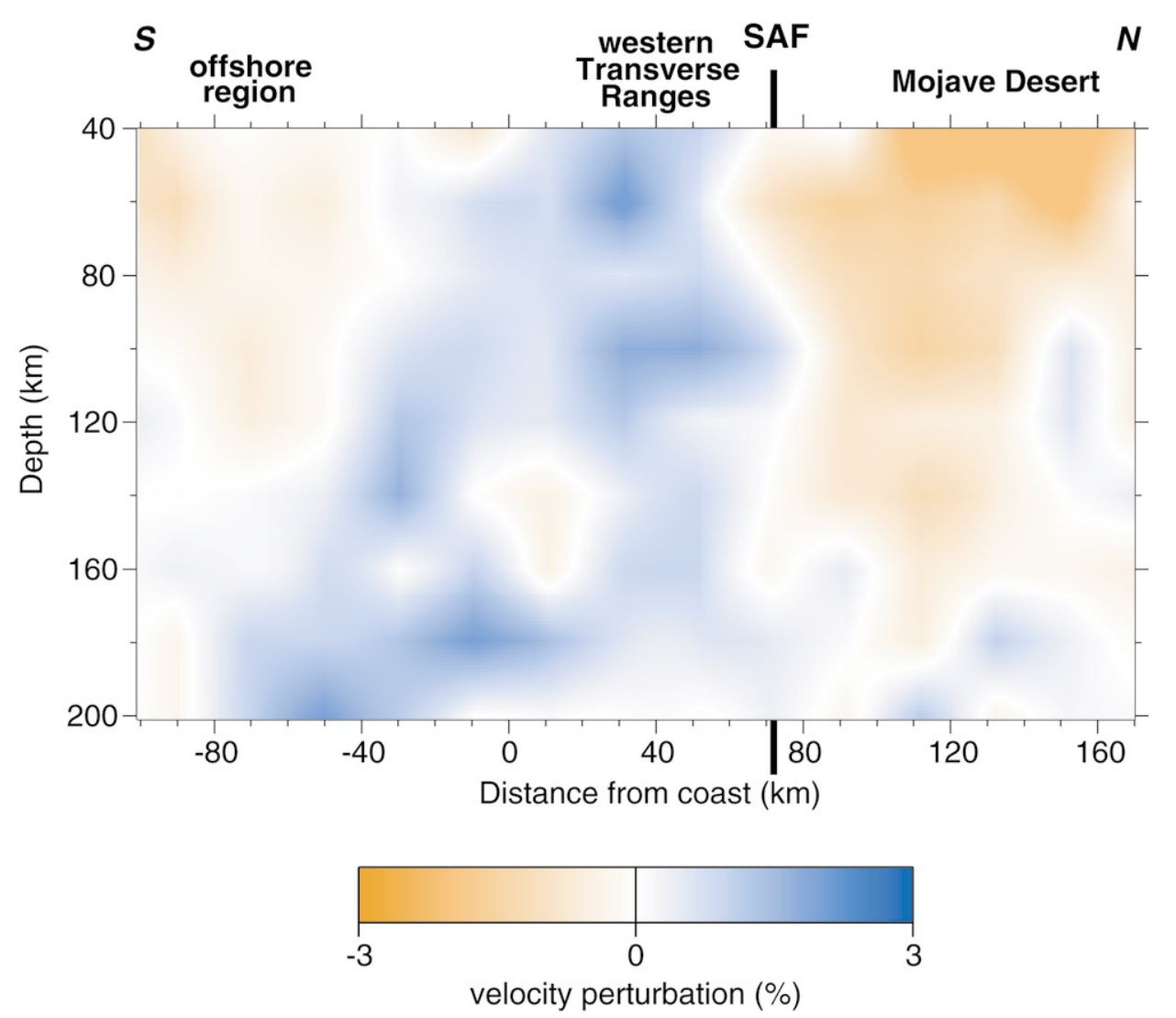

Figure 9. Uppermost mantle $P$-wave velocity cross section below the LARSE II array (see Fig. 1 for location). This cross section shows a high-velocity anomaly underlying the western Transverse Ranges where Magistrale et al. (2000) document thickened crust, but the anomaly is centered south of the San Andreas fault. The location of the San Andreas Fault is indicated by "SAF" and the heavy vertical black line.

west-southwest with depth. The western end of the anomaly breaks up at $\sim 150 \mathrm{~km}$ depth, the eastern end by $\sim 200 \mathrm{~km}$ depth implying lithospheric thickening of $50 \%$ and $100 \%$, respectively. High velocities also underlie the Peninsular Ranges and the southern San Joaquin Valley. The San Andreas fault lies at the center of crustal thickening and convergence in the eastern Transverse Ranges, but lies at the northern edge of thickening and convergence in the western Transverse Ranges. Version 3 of the reference three-dimensional seismic velocity model for Southern California is available as a FORTRAN source code and can be found on the SCEC Data Center website.

\section{Acknowledgments}

The LARSE and LABPSE experiments were made possible by the loan of SCEC Portable Broadband Instrument Center and IRIS PASSCAL seismometers, and the support of their staffs. We thank Ken Dueker for providing the large compilation of Southern California Seismic Network $P$ wave travel-time residual data. This research was supported by the Southern California Earthquake Center. SCEC is funded by NSF Cooperative Agreement EAR-8920136 and USGS Cooperative Agreements 14-08-0001A0899 and 1434-HQ-97AG01718. The SCEC Contribution Number for this article is 630 .

\section{References}

Anderson, O., and D. Isaak (1995). Elastic constants of mantle minerals at high temperature, in Mineral Physics and Crystallography: A Handbook of Physical Constants, T. J. Ahrens (Editor), AGU Reference Shelf, Vol. 2, American Geophysical Union, Washington DC, 64-97.

Artemieva, I. M., and W. D. Mooney (2001). Thermal thickness and evolution of Precambrian lithosphere; a global study, J. Geophys. Res. 106, 16,387-16,414.

Blythe, A. E., D. W. Burbank, K. A. Farley, and E. J. Fielding (2000). Structural and topographic evolution of the central Transverse Ranges, California, from apatite fission-track, (U-Th)/He and digital elevation model analyses, Basin Res. 12, 97-114.

Feigl., K. L., D. C. Agnew, Y. Bock, D. Dong, A. Donnellan, B. H. Hager, T. A. Herring, D. D. Jackson, T. H. Jordan, R. W. King, S. Larsen, K. M. Larson, M. H. Murray, Z. Shen, and F. H. Webb (1993). Space geodetic measurement of crustal deformation in Central and Southern California, 1984-1992, J. Geophys. Res. 98, 21,677-21,712.

Fuis, G. S., R. W. Clayton, P. M. Davis, T. Ryberg, W. J. Lutter, D. A. Okaya, E. Hauksson, C. Prodehl, J. M. Murphy, M. L. Benthien, S. A. Baher, M. D. Kohler, K. Thygesen, G. Simila, and G. R. Keller (2003). Fault systems of the 1971 San Fernando, and 1994 Northridge earthquakes, southern California: Relocated aftershocks and seismic images from LARSE II, Geology 31, 171-174.

Hadley, D., and H. Kanamori (1977). Seismic structure of the Transverse Ranges, California, Geol. Soc. Am. Bull. 88, 1469-1478.

Hearn, T. M., and R. W. Clayton (1986). Lateral velocity variations in 
Southern California. II. Results for the lower crust from Pn waves, Bull. Seism. Soc. Am. 76, 511-520.

Houseman, G. A., E. A. Neil, and M. D. Kohler (2000). Lithospheric instability beneath the Transverse Ranges of California, J. Geophys. Res. 105, 16,237-16,250.

Humphreys, E. D., and R. W. Clayton (1990). Tomographic image of the Southern California mantle, J. Geophys. Res. 95, 19,725-19,746.

Humphreys, E. D., and K. G. Dueker (1994). Western U.S. upper mantle structure, J. Geophys. Res. 99, 9615-9634.

Humphreys, E. D., and B. H. Hager (1990). A kinematic model for the late Cenozoic development of southern California crust and upper mantle, J. Geophys. Res. 95, 19,747-19,762.

Humphreys, E. D., R. W. Clayton, and B. H. Hager (1984). A tomographic image of mantle structure beneath Southern California, Geophys. Res. Lett. 11, 625-627.

Jackson, J., and P. Molnar (1990). Active faulting and block rotations in the western Transverse Ranges, California, J. Geophys. Res. 95, 22,073-22,087.

Kennett, B. L. N., and E. R. Engdahl (1991). Traveltimes for global earthquake location and phase identification, Geophys. J. Int. 105, 429465.

Kohler, M. D. (1999). Lithospheric deformation beneath the San Gabriel Mountains in the Southern California Transverse Ranges, J. Geophys. Res. 104, 15,025-15,041.

Kohler, M. D., and B. C. Kerr (2002). Report for passive data acquired in the 1998-1999 Los Angeles Region Seismic Experiment II: a transect from Santa Monica Bay to the westernmost Mojave Desert, USGS Open-File Report 02-329.

Kohler, M. D., B. C. Kerr, and P. M. Davis (2000). The 1997 Los Angeles Basin Passive Seismic Experiment-a dense, urban seismic array to investigate basin lithospheric structures, USGS Open-File Report 00148, 109 pp.

Kohler, M. D., D. J. Wald, and R. W. Graves (1998). The effect of localized sedimentary environment and subsurface structure variations on teleseismic waveform amplitudes in the Los Angeles Basin, EOS 79, F605.

Kohler, M. D., P. M. Davis, H. Liu, M. Benthien, S. Gao, G. S. Fuis, R. W. Clayton, D. Okaya, and J. Mori (1996). Data Report for the 1993 Los Angeles Region Seismic Experiment (LARSE93), Southern California: a passive study from Seal Beach northeastward through the Mojave Desert, USGS Open-File Report 96-85, 82 pp.

Magistrale, H., S. Day, R. W. Clayton, and R. Graves (2000). The SCEC Southern California Reference Three-Dimensional Seismic Velocity Model Version 2, Bull. Seism. Soc. Am. 90, S65-S76.
Marcinkovich, C., and T. Tanimoto (2000). CMT inversion via heterogeneous Green's Functions: a spherical finite-difference approach, EOS 81, F870.

Paige, C. C., and M. A. Saunders (1982a). LSQR: an algorithm for sparse linear equations and sparse least squares, ACM Trans. Math Software 8, 43-71.

Paige, C. C., and M. A. Saunders (1982b). Algorithm 582, LSQR: sparse linear equations and least squares problems, ACM Trans. Math Software 8, 195-209.

Prindle, K., and T. Tanimoto (2000). Southern California 2D wavefield reconstruction: Mpeg movies, EOS 81, F899.

Raikes, S. A. (1980). Regional variations in upper mantle structure beneath Southern California, Geophys. J. R. Astr. Soc. 63, 187-216.

Richards-Dinger, K. B., and P. M. Shearer (1997). Estimating crustal thickness in Southern California by stacking PmP arrivals, J. Geophys. Res. 102, 15,211-15,214.

Shen, Z., D. D. Jackson, and B. X. Ge (1996). Crustal deformation across and beyond the Los Angeles basin from geodetic measurements, $J$. Geophys. Res. 101, 27,957-27,980.

Snay, R. A., M. W. Cline, C. R. Philipp, D. D. Jackson, Y. Feng, Z.-K. Shen, and M. Lisowski (1996). Crustal velocity field near the big bend of California's San Andreas Fault, J. Geophys. Res. 101, 3173-3185.

Department of Earth and Space Sciences

University of California, Los Angeles

Los Angeles, California 90095-1567

kohler@ess.ucla.edu

(M.D.K.)

Department of Geological Sciences

San Diego State University

San Diego, California 92182-1020

(H.M.)

Seismological Laboratory 252-21

California Institute of Technology

Pasadena, California 91125

(R.W.C.)

Manuscript received 12 January 2002. 